\title{
Seasonal variations in temperature and salinity in the gulf of guinea
}

\begin{abstract}
A simple linear regression model was used to determine variations in temperature and salinity profile in the coastal waters of Ghana in Gulf of Guinea (GOG) from four surveys, two from each hydrographic season conducted between 2000 and 2002. The model estimated an average sea surface temperature (SST) of $27.13^{\circ} \mathrm{C}$ for thermocline season and $22.52^{\circ} \mathrm{C}$ for upwelling season. The average sea surface salinity (SSS) estimated by the model for the thermocline season was $35.24 \%$ and the upwelling season was $35.56 \%$. A seasonal sea surface temperature (SST) variability of $4.61^{\circ} \mathrm{C}$ was observed in the GOG. This revealed that that seasonal SST variability in the Gulf of Guinea (GOG) has reduced. The changes in temperature and salinity with unit change in depth did not show any clear pattern between thermocline and upwelling seasons. Temperatures showed higher level of correlation with changes in depth than salinity. The range of temperature within the 80-metre water column was higher in the upwelling season than the thermocline season. The range of salinity however did not show any clear pattern between the thermocline and upwelling seasons. There were no significant differences in temperature and salinity between the two upwelling seasons. There were however significant differences in temperature and salinity between the two thermocline seasons. The reduction in seasonal variability of SST in the GOG has implications for marine life in the region.
\end{abstract}

Keywords: Temperature, Salinity, Upwelling, Thermocline, Seasonal variability, Ghana, Gulf of Guinea, West Africa, Guinea Current Large Marine Ecosystem
Volume 4 Issue 2 - 2016

Emmanuel K Dovlo

Marine Fisheries Research Division, Ghana

Correspondence: Emmanuel K Dovlo, Marine Fisheries Research Division, Fisheries Commission, P.O. Box BT-62,Tema, Ghana, West Africa, Tel +233-26-2120664,

Emailemkwdo@yahoo.uk

Received: November 18, 2015 | Published: February 26, 2016
Abbreviations: GOG, Gulf of Guinea; SST, Sea Surface Temperature; SSS, Sea Surface Salinity; GCLME, Guinea Current Large Marine Ecosystem

\section{Introduction}

The marine environment is influenced by a number of physical and chemical factors including temperature and salinity. The marine ecosystem is in a continuous state of motion and variations of these factors, singly or in combination with others can greatly influence the distributions of marine organisms in their communities. Variations in temperature and salinity can define certain water masses characteristics important for distinguishing and classifying different waters. Large scale physical forcing determines most of the dynamics of marine populations. ${ }^{1}$ The coastal hydrography of Gulf of Guinea (GOG) is generally divided into four regimes; a minor upwelling from December to January; long developed thermocline from February to June; major upwelling season from July to September; and another developed thermocline from October to November., ${ }^{2,3}$ During the developed thermocline periods, increased insolation and coastal rains produce a very stable stratification with well-mixed surface layer 30-40 metres deep overlying a very sharp pycnocline. ${ }^{4}$ During the upwelling, the thermocline weakens and rises to the surface. There is no seasonal variation in the hydrographic structure below 100 metres, and the upwelled water come from a depth of 80-100 metres. The GOG is characterised by a shallow thermocline associated with the eastward shoaling of the thermal structure at low latitudes. The GOG is a region of the tropical Atlantic where seasonal variability of sea surface temperature (SST) has the largest amplitude of $5^{\circ} \mathrm{C}$ $7^{\circ} \mathrm{C}$ compared to small amplitude of $1{ }^{\circ} \mathrm{C}-2^{\circ} \mathrm{C}$ further in the western tropical Atlantic. ${ }^{6}$ The main aim of this paper is to determine seasonal variations in the vertical structure of temperature and salinity in the GOG. The seasonal upwelling of the region, which controls biological activities, is driven mainly by changes in temperature and salinity characteristics of the water. This study can help understand certain underlying factors affecting marine community dynamics.

\section{Materials and methods}

The Gulf of Guinea (GOG) is located within Guinea Current Large Marine Ecosystem (GCLME). The coast of GOG stretches over 2,000 $\mathrm{km}$ between $8^{\circ} \mathrm{W}$ on the left boundary, $9^{\circ} \mathrm{E}$ on the right boundary and $5^{\circ} \mathrm{N}$ on the top boundary ${ }^{7}$ (Figure 1 ).

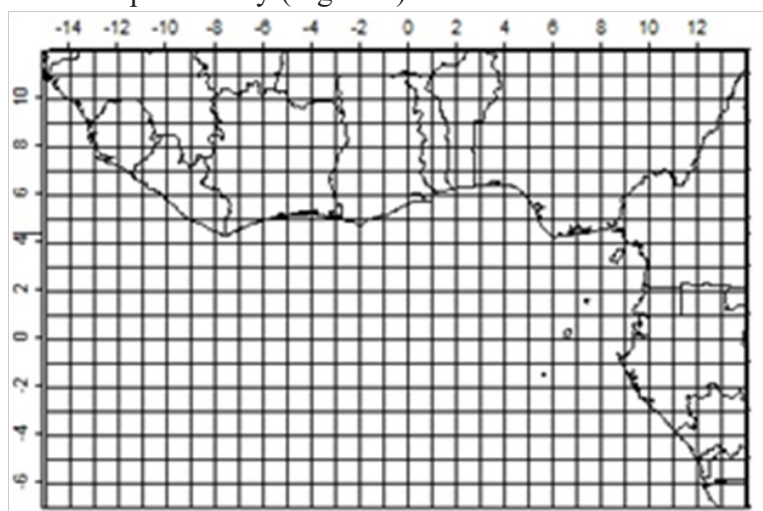

Figure I Map of the Guinea Current Large Marine Ecosystem (GCLME) showing the study area of Gulf of Guinea (GOG) located between $-8^{\circ}\left(8^{\circ} \mathrm{W}\right)$ on the left boundary and $9^{\circ}\left(9^{\circ} \mathrm{E}\right)$ on the right boundary. Ghana can be found between $-3^{\circ}\left(3^{\circ} \mathrm{W}\right)$ and $\mathrm{I}^{\circ}\left(\mathrm{I}^{\circ} \mathrm{E}\right)$.

Four surveys were conducted between 2000 and 2002, each taking a period of two to three weeks in the coastal waters of Ghana. The first and third surveys were conducted in thermocline seasons whilst the second and fourth surveys in upwelling seasons. The periods for 
surveys were as follows: 4-18 October 2000 (first survey), 25 July - 13 August 2001(second survey), 29 October - 16 November 2001 (third survey) and 20 July - 5 August 2002 (fourth survey). Data were collected from 50 stations in each survey from ten transects along the coast of Ghana ( $3 \mathrm{~W}$ to $1 \mathrm{E}$ ). The data were collected between the depths of 20 metres and 80 metres except the first survey where data were collected from depth as shallow as 10 metres. The oceanographic equipment used was Chlorotech DCL1180-PDK equipped with a 180 meter long plumb cable. The Chlorotech was equipped with sensors to measure temperature and salinity among others.

In preparation for deployment of Chlorotech instrument, chains and lead weight were attached to the rope instrument to prevent sensor from being carried away by current. The sensor was then vertically dropped to a depth of about $50 \mathrm{~cm}$ and equipment calibration performed. After calibration, continuous observation were conducted and recorded by lowering the sensor into the sea at a speed of 1 meter per second to the desired depth. However there were instances where observation down to those desired depths could not be conducted because the plumb cable was swept away by strong current and as a result the cable could not reach the desired depths. In those instances observations were made at the deepest possible depth as permitted by the length of cable. Recorded data on the Chlorotech equipment was transferred into a computer in a Microsoft Excel format.

Temperature and salinity data in each survey were averaged over 10-metre depth intervals. The temperature and salinity for same depth in each hydrographic season were pooled together. Excel scatter plots were made for temperature and salinity data separately for each thermocline and upwelling seasons in the four surveys. A linear trend line was added to the plot to fit a linear model.

The relationship between depth, $\mathrm{d}$ and the parameter, $\mathrm{p}$ was investigated using a linear regression model of the form:

$$
d=m p+c
$$

where $\mathrm{m}$ and $\mathrm{c}$ are constants, $\mathrm{d}$ is depth and $\mathrm{p}$ is the parameter of interest (temperature and salinity). $\mathrm{m}$ is the gradient and explains the change in parameter value associated with a unit change in depth, $\mathrm{d}$. $\mathrm{c}$ is the $\mathrm{y}$-intercept and represents the value of the parameter when depth, $\mathrm{d}$ is zero.

A t-test was performed to determine whether there were significant differences in temperature and salinity between the two thermocline seasons and between the two upwelling seasons.

\section{Results}

In the first survey (thermocline season), a unit (one metre) increase in depth resulted in $0.07^{\circ} \mathrm{C}$ drop in temperature and sea surface temperature (SST) was estimated at $25.46^{\circ} \mathrm{C}$ (Figure 2). In the third survey (thermocline season), a unit increase in depth resulted in $0.04^{\circ} \mathrm{C}$ drop in temperature and SST was estimated at $28.80^{\circ} \mathrm{C}$ (Figure 3). In the second survey (upwelling season), a unit increase in depth resulted in $0.04^{\circ} \mathrm{C}$ drop in temperature and SST was estimated at $21.82^{\circ} \mathrm{C}$ (Figure 4 ). In the fourth survey (upwelling season), a unit increase in depth resulted in $0.06^{\circ} \mathrm{C}$ drop in temperature and SST was estimated at $23.22^{\circ} \mathrm{C}$ (Figure 5).

In the first survey (thermocline season), a unit increase in depth resulted in 0.001 raise in salinity and sea surface salinity (SSS) was estimated at $35.55 \%$ (Figure 6). In the third survey (thermocline season), a unit increase in depth resulted in 0.005 raise in salinity and SSS was estimated at $34.93 \%$ (Figure 7). In the second survey (upwelling season), a unit increase in depth resulted in 0.001 raise in salinity and SSS was estimated at $35.60 \%$ (Figure 8). In the fourth survey (upwelling season), a unit increase in depth resulted in 0.003 raise in salinity and SSS was estimated at $35.51 \%$ (Figure 9).

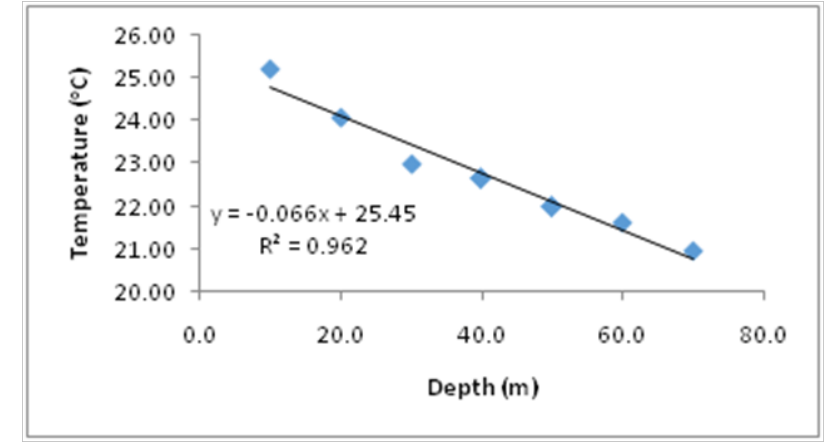

Figure 2 Variations in temperature with depth in the first survey (thermocline season).

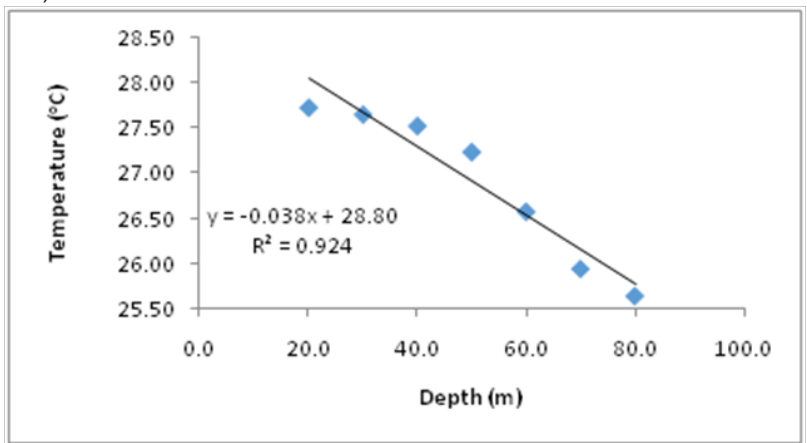

Figure 3 Variations in temperature with depth in the third survey (thermocline season).

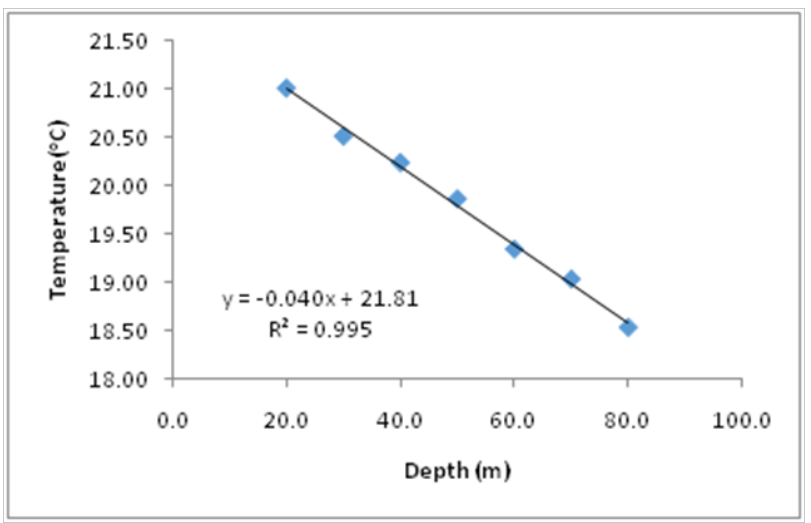

Figure 4 Variations in temperature with depth in the second survey (upwelling season).

The minimum and maximum temperatures and salinities, together with their ranges from the first to fourth survey have been shown (Table 1). The highest range of temperature was recorded during the fourth survey (upwelling season) whilst the lowest range of temperature was recorded in the first survey (thermocline season). The highest range of salinity was recorded during the third survey (thermocline season) whilst the lowest range of salinity was recorded in the first survey (thermocline season). The range of temperature was higher during the upwelling season than the thermocline season. The range of salinity however did not show any clear pattern between the thermocline and upwelling seasons. 


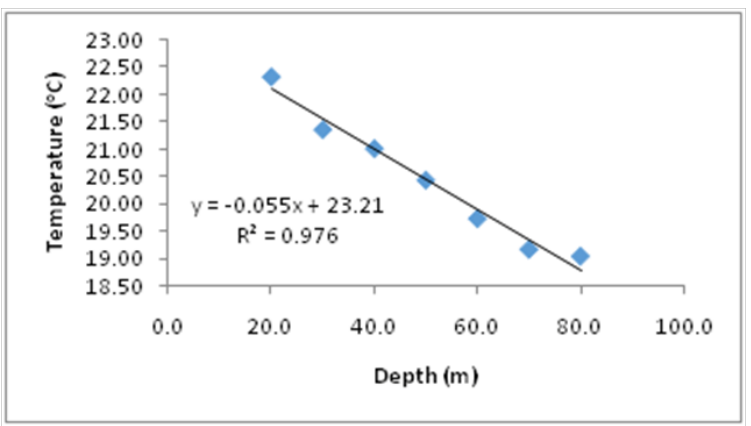

Figure $\mathbf{5}$ Variations in temperature with depth in the fourth survey (upwelling season).

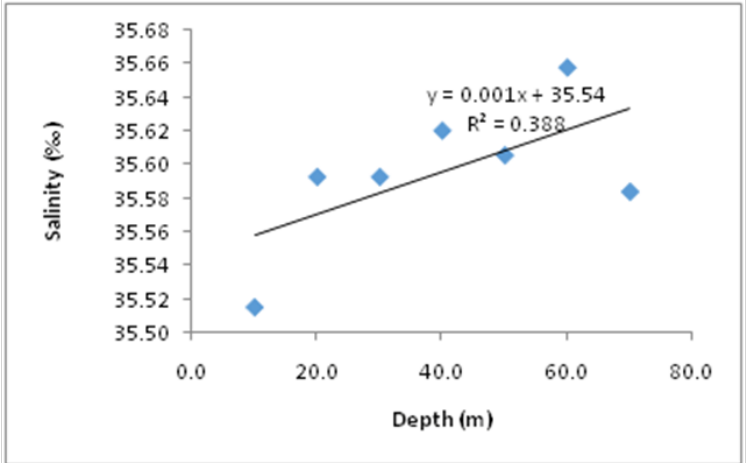

Figure $\mathbf{6}$ Variations in salinity with depth in first survey (thermocline season).

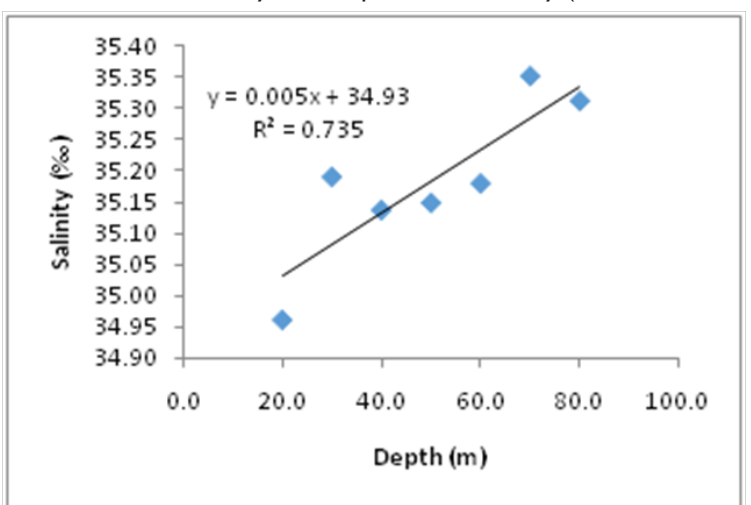

Figure 7 Variations in salinity with depth in third survey (thermocline period).

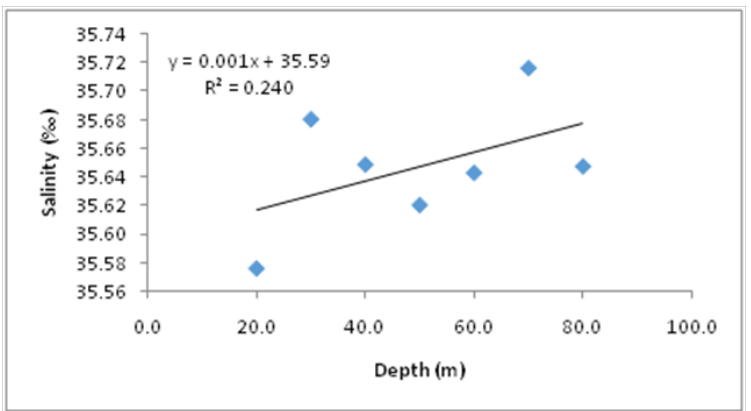

Figure 8 Variations in salinity with depth in the second survey (upwelling season).

Variations in temperature and salinity in the four surveys from the linear regression model have been summarized below (Table 2). The average SST was estimated at $27.13^{\circ} \mathrm{C}$ for the thermocline season and $22.52^{\circ} \mathrm{C}$ for the upwelling season. The seasonal SST variability of
4.61 was thus observed. The average SSS was estimated at $35.24 \%$ o for the thermocline season and $35.56 \%$ for the upwelling season. The change in temperature and salinity with unit change in depth did not show any clear pattern between thermocline and upwelling seasons. The coefficient of determination (R2) was however higher $(>0.92)$ with temperatures showing higher degree of correlation with depth than salinity.

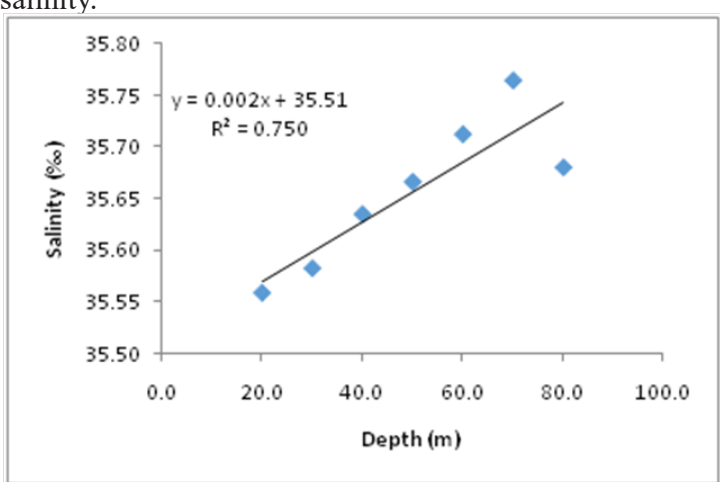

Figure 9 Variations in salinity with depth in the fourth survey (upwelling season).

Table I The minimum, maximum and ranges of temperatures and salinities from the first to fourth survey

\begin{tabular}{|c|c|c|c|c|c|c|c|}
\hline \multirow{2}{*}{ Survey } & \multirow{2}{*}{ Season } & \multicolumn{5}{|c|}{ Temperature $\left({ }^{\circ} \mathrm{C}\right)$ Salinity (\%o) } & \multirow[b]{2}{*}{ range } \\
\hline & & $\min$ & $\max$ & range & $\min$ & $\max$ & \\
\hline First & Thermocline & 22.80 & 26.16 & 3.36 & 35.189 & 35.833 & 0.644 \\
\hline Second & Upwelling & 18.42 & 22.19 & 3.77 & 34.856 & 35.806 & 0.950 \\
\hline Third & Thern & 24.86 & 28.28 & 3.42 & 34.287 & 35.471 & 1.184 \\
\hline Fourth & Upwelling & 8.63 & 22.96 & 4.33 & 35.012 & 35.789 & 0.777 \\
\hline
\end{tabular}

The results of t-test for the two thermocline seasons showed that there were significant differences in temperature between the two thermocline seasons $(\mathrm{P}<0.05)$ (Table 3$)$. The results of t-test for the two upwelling seasons showed that there were no significant differences in temperature between the two upwelling seasons $(\mathrm{P}>0.05)$ (Table 4).

\section{Discussion}

The study revealed lower temperatures and higher salinities during the upwelling seasons in the Gulf of Guinea. Lower temperatures and higher salinities were reported during the upwelling season in the coastal waters of Ghana in the Gulf of Guinea (GOG) ${ }^{8}$ The shoaling of thermocline during upwelling season permitted upward movement of cold water enriched with nutrients and other salts which lowers temperature and increases salinity in the well mixed region water column. The range of temperature between the surface and the 80 -metre depth were higher in upwelling seasons than thermocline seasons. This is in contrast to a well-mixed upwelling ecosystems, where mixing produces a water column with less variations in temperature compared to stable thermocline season. In the upwelling season, the thermocline weakens and rises to the surface. ${ }^{5}$ The breaking of the thermocline mixes the water column and makes the water more uniform and less variable in temperature in the upwelling season. Stable stratification generated by thermocline in thermocline seasons, on the other hand, would prevent mixing of water column and enhance greater variations in temperature. The minimum temperatures recorded in the 80 -metre depth were lower than the $20^{\circ} \mathrm{C}$ isotherm which usually marks the position of the thermocline in the GOG (Table 1). This might be an indication of the shallowing of the thermocline to depth lower than 80 metres. In the Gulf of Guinea, there is no seasonal variation in the hydrographic structure below 100 metres, and the upwelled water come from a depth of 80-100 metres. ${ }^{5}$ 
Table 2 Summary of the variations in temperature and salinity obtained from linear regression model from first to fourth survey. The gradient ( $m$ ) explains the change in parameter value associated with a unit change in depth whilst the intercept (c) is the $y$-intercept and represents the value of the parameter when depth (d) is zero

\begin{tabular}{|c|c|c|c|c|c|c|c|}
\hline \multirow{2}{*}{ Survey } & \multirow{2}{*}{ Season } & \multicolumn{3}{|c|}{ Temperature $\left({ }^{\circ} \mathrm{C}\right)$} & \multicolumn{3}{|l|}{ Salinity (\%) } \\
\hline & & Gradient (m) & Intercept (c) & $\mathbf{R}^{2}$ & Gradient (m) & Intercept (c) & $\mathbf{R}^{2}$ \\
\hline First & Thermocline & 0.07 & 25.46 & 0.963 & 0.001 & 35.55 & 0.389 \\
\hline Second & Upwelling & 0.04 & 21.82 & 0.995 & 0.001 & 35.60 & 0.240 \\
\hline Third & Thermocline & 0.04 & 28.80 & 0.925 & 0.005 & 34.93 & 0.735 \\
\hline Fourth & Upwelling & 0.06 & 23.22 & 0.977 & 0.003 & 35.51 & 0.750 \\
\hline
\end{tabular}

Table 3 Results of t-test showing significant differences in temperatures between the two thermocline seasons

\begin{tabular}{|c|c|c|c|}
\hline \multicolumn{4}{|c|}{ F-Test Two-Sample for Variances } \\
\hline & First Survey & \multicolumn{2}{|l|}{ Third Survey } \\
\hline Mean & 22.44621057 & \multicolumn{2}{|l|}{26.90500631} \\
\hline Variance & 1.040008708 & \multicolumn{2}{|l|}{0.727386392} \\
\hline Observations & 7 & \multicolumn{2}{|l|}{7} \\
\hline Df & 6 & \multicolumn{2}{|l|}{6} \\
\hline $\mathrm{F}$ & \multicolumn{3}{|l|}{1.429788513} \\
\hline$P(F<=f)$ one-tail & \multicolumn{3}{|l|}{0.33759854} \\
\hline F Critical one-tail & \multicolumn{3}{|c|}{$4.2838657 \mid 4$} \\
\hline \multicolumn{4}{|c|}{ t-Test:Two-Sample Assuming Equal Variances } \\
\hline & & First Survey & Third Survey \\
\hline Mean & & 22.44621057 & 26.90500631 \\
\hline Variance & & 1.040008708 & 0.727386392 \\
\hline Observations & & 7 & 7 \\
\hline Pooled Variance & & 0.88369755 & \\
\hline Hypothesized Mea & rence & 0 & \\
\hline Df & & 12 & \\
\hline t Stat & & $-8.87359848 \mid$ & \\
\hline $\mathrm{P}(\mathrm{T}<=\mathrm{t})$ one-tail & & 6.408I7E-07 & \\
\hline t Critical one-tail & & I.782287556 & \\
\hline$P(T<=t)$ two-tail & & $1.28163 \mathrm{E}-06$ & \\
\hline t Critical two-tail & & 2.17881283 & \\
\hline
\end{tabular}

Table 4 Results of t-test showing no significant differences in temperatures between the two upwelling seasons

\begin{tabular}{|c|c|c|c|}
\hline \multicolumn{4}{|c|}{ F-Test Two-Sample for Variances } \\
\hline & Second Survey & \multicolumn{2}{|c|}{ Fourth Survey } \\
\hline Mean & 19.79827554 & \multicolumn{2}{|c|}{20.44645672} \\
\hline Variance & 0.765851666 & \multicolumn{2}{|c|}{1.46740669} \\
\hline Observations & 7 & \multicolumn{2}{|c|}{7} \\
\hline Df & 6 & \multicolumn{2}{|l|}{6} \\
\hline $\mathrm{F}$ & \multicolumn{3}{|l|}{0.521908256} \\
\hline$P(F<=f)$ one-tail & \multicolumn{3}{|l|}{0.224295755} \\
\hline F Critical one-tail & \multicolumn{3}{|l|}{0.233434021} \\
\hline \multicolumn{4}{|c|}{ t-Test:Two-Sample Assuming Equal Variances } \\
\hline & \multicolumn{2}{|c|}{ Second Survey } & Fourth Survey \\
\hline Mean & & 19.79827554 & 20.44645672 \\
\hline Variance & & 0.765851666 & 1.46740669 \\
\hline Observations & & 7 & 7 \\
\hline \multicolumn{2}{|l|}{ Pooled Variance } & \multicolumn{2}{|l|}{1.116629178} \\
\hline \multicolumn{2}{|c|}{ Hypothesized Mean Difference } & \multicolumn{2}{|l|}{0} \\
\hline \multicolumn{2}{|c|}{ Df } & \multicolumn{2}{|l|}{12} \\
\hline \multicolumn{2}{|l|}{ t Stat } & \multicolumn{2}{|l|}{$-1 .|4756| 457$} \\
\hline \multicolumn{2}{|l|}{$\mathrm{P}(\mathrm{T}<=\mathrm{t})$ one-tail } & \multicolumn{2}{|l|}{0.136756997} \\
\hline \multicolumn{2}{|l|}{ t Critical one-tail } & \multicolumn{2}{|l|}{ I.782287556 } \\
\hline \multicolumn{2}{|l|}{$\mathrm{P}(\mathrm{T}<=\mathrm{t})$ two-tail } & \multicolumn{2}{|l|}{0.273513994} \\
\hline t Critical two-tail & & \multicolumn{2}{|l|}{2.17881283} \\
\hline
\end{tabular}

In this study, a seasonal sea surface temperature (SST) variability of $4.6^{\circ} \mathrm{C}$ was observed in the GOG. A seasonal SST variability of $5^{\circ} \mathrm{C}-7^{\circ} \mathrm{C}$ in the GOG has been reported. ${ }^{6}$ Extreme sea surface temperature variability greater than $8^{\circ} \mathrm{C}$ has earlier been reported in the 1960 s and 1970s in GOG. ${ }^{5}$ Thus there is a gradual reduction of seasonal SST variability in the GOG. The reduction in seasonal variability of SST in GOG is due to the warming trend being observed in the region and consequent weakening of the major upwelling. There was a gradual warming of SST in the major upwelling season. ${ }^{9}$ A reduction in strength of the major upwelling has earlier been reported. ${ }^{10} \mathrm{~A}$ reduction in the strength of the major upwelling increases the minimum temperatures and reduces the seasonal variation in temperature. This can have significant impacts on biological activities and affect marine life. Unlike temperature, salinity exhibits a conservative property and does 
not vary widely between the seasons. However with the warming trend being observed in the GOG, salinities can alter in the region changing the characteristic physicochemical properties of its waters. High levels of physical stress especially in upwelling areas can place significant biological constraints on marine life and proper ecosystem functioning. ${ }^{11}$

\section{Conclusion}

The model estimated an average sea surface temperature (SST) of $27.13^{\circ} \mathrm{C}$ for the thermocline season and $22.52^{\circ} \mathrm{C}$ for the upwelling season. The average sea surface salinity (SSS) was estimated at $35.24 \%$ or the thermocline season and $35.56 \%$ or the upwelling season. This study has revealed that seasonal sea surface temperature (SST) variability in the Gulf of Guinea (GOG) has reduced. A seasonal SST variability of $4.61{ }^{\circ} \mathrm{C}$ was observed in the GOG. The change in temperature and salinity with unit change in depth did not show any clear pattern between thermocline and upwelling seasons. Temperatures showed higher degree of correlation with changes in depth than salinity. The range of temperature was higher during the upwelling season than the thermocline season. The range of salinity however did not show any clear pattern between the thermocline and upwelling seasons. There were no significant differences in temperature and salinity between the two upwelling seasons. There were however significant differences in temperature and salinity between the two thermocline seasons. The reduction in seasonal variability of SST in the GOG has implications for marine life in the life in the region.

\section{Acknowledgements}

The author thanks his colleagues from Marine Fisheries Research Division who were part of the survey team with him for the collection of the data and the Japanese counterparts from JANUS Company Ltd., Japan. The oceanographic data was collected as part of a survey on stock assessment of demersal fish species in Ghana with support from the Government of Japan through Japan International Cooperation Agency (JICA).

\section{Conflicts of interest}

None.

\section{References}

1. Steele JH. From carbon flux to regime shift. Fish. Oceanogr. 1998;7(34):176-181.

2. Longhurst AR. A review of oceanography of the Gulf of Guinea. Bulletin d'Institute franc Africain noire. 1962;24:633-663.

3. Mensah MA, Koranteng KA. A review of the oceanography and fisheries resources in the coastal waters of Ghana, 1981-1986. Fisheries Research and Utilisation Branch, Fisheries Department, Tema, Ghana. 1988;p.35.

4. Houghton RW, Mensah MA. Physical aspects and biological consequences of Ghanaian coastal upwelling. In: Boje R \& Tomczak M (Eds.), Upwelling ecosystems. Springer-Verlag Berlin, Heidelberg, Germany. 1978;pp.167-180.

5. Houghton RW. Circulation and hydrographic structure over the Ghana continental shelf during the 1974 Upwelling. J Phys Oceanogr. 1976;6:909-924.

6. Busalacchi AJ, Picaut J Seasonal variability from a model of the tropical Atlantic Ocean. J Phys Oceanogr. 1983;13:1564-1588.

7. Allersma E, Wiel M, Tilman K. Coastal conditions in West Africa - A Review. Ocean and Coastal Management. 1993;19(3):199- 240.

8. Anang ER. Seasonal cycle of the phytoplankton in the coastal waters of Ghana. Hydrobiologia. 1979;62(1):33-45.

9. Wiafe G, Yaqub HB, Mensah MA, et al. Impact of climate change on long-term zooplankton biomass in the upwelling region of the Gulf of Guinea. ICES Journal of Marine Science. 2008;65:318-324

10. Pezennec O, Bard FX. Importance ecologique de la petite saison d'upwelling ivoiri-ghaneenne et changements dans la pecherie de Sardinella aurita. Aquatic Living Resources. 1992;5:249-259.

11. Hardman-Mountford NJ, McGlade JM. Variability of physical environmental processes in the Gulf of Guinea and implications for fisheries recruitment. An investigation using remotely sensed sea surface temperature. In: McGlade JM, et al. (Eds.), Gulf of Guinea Large Marine Ecosystem, Elsevier Science. 2002;11:49-66. 